Journal of Biotechnology and Strategic Health Research
Araştırma Makalesi /Research Article
http://dergipark.org.tr/tr/pub/bshr

\title{
Yoğun Bakım Ünitesinde Gelişen Kandidemi Olgularının Prognozları ve Risk Faktörlerinin Değerlendirilmesi-Tek Merkez
}

\author{
Evaluation of Prognoses and Risk Factors of Candidemia Cases Developing in \\ The Intensive Care Unit-Single Center
}

\author{
iD Şenay Öztürk Durmaz', iD Ayşenur Sümer Coşkun² \\ ${ }^{1}$ Kepez Devlet Hastanesi Enfeksiyon Hastalıkları ve Klinik Mikrobiyoloji Klinigi, Kepez/Antalya, Turkey \\ ${ }^{2}$ Kepez Devlet Hastanesi, Anestezi ve Reanimasyon Kliniği, Kepez/Antalya, Turkey \\ ORCID ID: Şenay Öztürk Durmaz https://orcid.org/0000-0002-5260-2682, Ayșenur Sümer Coşkun https://orcid.org/0000-0001-9791-1510 \\ ^Sorumlu Yazar / Corresponding Author: Dr. Şenay Öztürk Durmaz, e-posta / e-mail: drsenay70@gmail.com \\ Geliş Tarihi / Received : 17-07-2021 Kabul Tarihi / Accepted: 11-08-2021 Yayın Tarihi / Online Published: 30-08-2021 \\ Durmaz Ş.ö., Coşkun A.S. Yoğun Bakım Ünitesinde Gelişen Kandidemi Olgularının Prognozları ve Risk Faktörlerinin Değerlendirilmesi- \\ Tek Merkez, J Biotechnol and Strategic Health Res. 2021;5(2):148-153
}

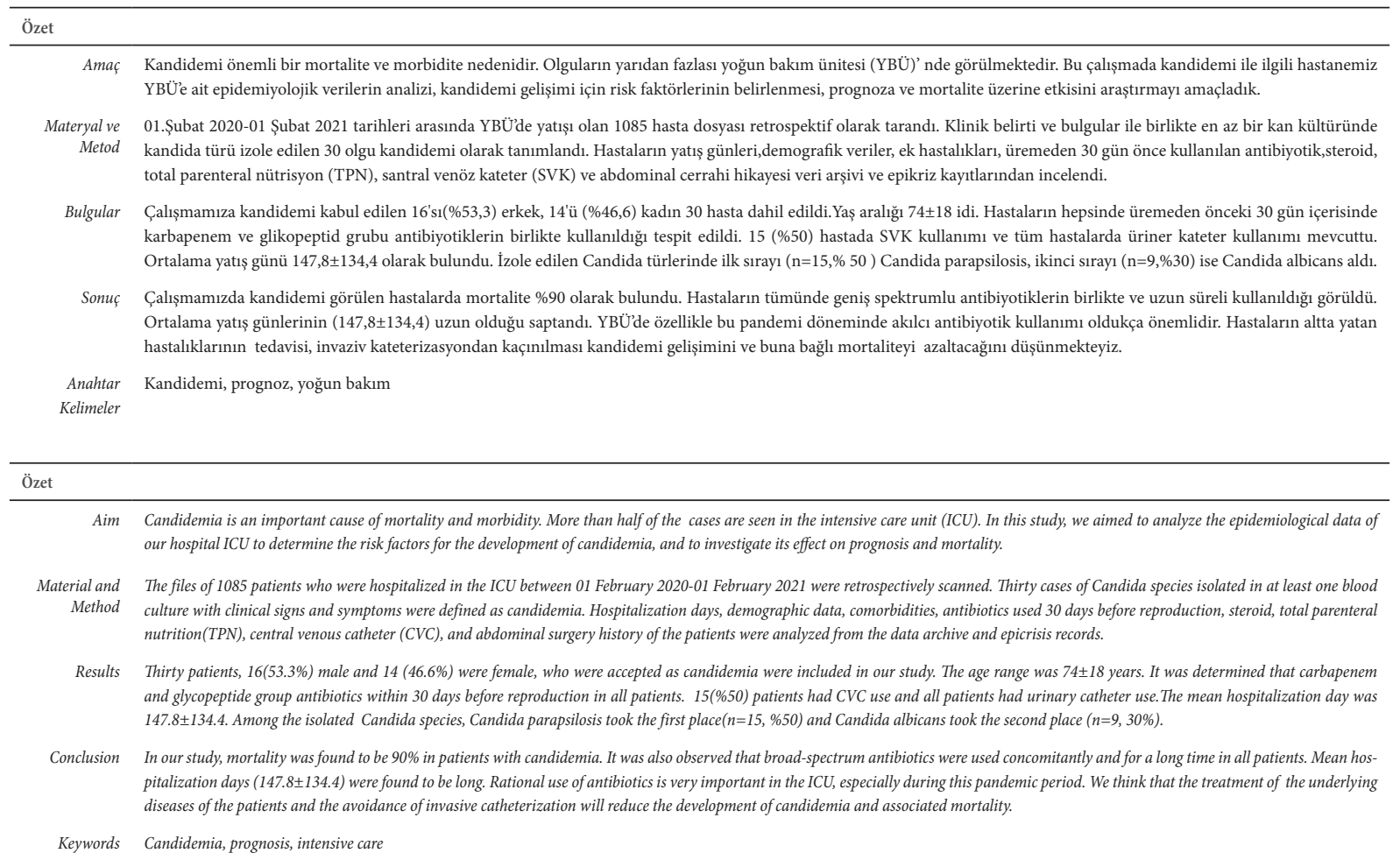




\section{GíRiș}

Kandidemi olgularının yarıdan fazlası yoğun bakım ünitesi (YBÜ)'nde görülmektedir. ${ }^{1,2}$ YBÜ'de hastada kandida enfeksiyonu gelişmesi mortalite için bağımsız risk faktörleri arasındadır. ${ }^{3}$ Invaziv kandida enfeksiyonlarının mortalitesi farklı yayınlarda \%39-60 arasında değişmektedir. ${ }^{4-6}$ $\mathrm{Bu}$ hastalarda yüksek mortalitenin yanı sıra hastanede yatış süresinin uzaması ve tedavide kullanılan ajanlar nedeniyle ekonomik yükün artması da başka bir sorundur. ${ }^{7}$ İnvaziv kandida enfeksiyonlarının \%40-60'ına C.albicans neden olmaktadir. Ancak laboratuvar tekniklerinin ilerlemesi ile yeni türlerin tanımlanabilmesi ve yaygın flukonazol kullanımı gibi nedenlerle eskiden patojen olmayan türlerin ve albicans dışı kandida türlerinin sayısı giderek artmaktadir. ${ }^{8,9}$

Genel olarak invaziv kandida enfeksiyonu için risk faktörleri arasında 65 yaş üzerinde olmak, yüksek "acute physiologic assessment and chronic health evaluation" (APACHE) II skoru, balgam ve dışkı gibi örneklerde bilinen kandida kolonizasyonu, santral venöz kateter olması, uzun süreli geniş spektrumlu antibiyotik kullanımı, abdominal cerrahi uygulanmış olması, parenteral beslenme, ağır mukozit, malignite, solid organ nakli ve böbrek yetmezliği olması sayılabilir. ${ }^{10,11}$

Kandida lokal epidemiyolojisini sadece hastane genelinde değil, ünite düzeyinde de bilmek, uygun ampirik veya preemptif tedaviyi başlamak açısından önemlidir. Tedavi başlanmasındaki gecikmenin mortalite üzerinde etkileri gösterilmiştir. ${ }^{12}$ Doğru ve hızlı tedavi başlamada en büyük engel tanı koymadaki zorluktur. Tanıda klinik inceleme, kültür, radyolojik bulgular ve histopatoloji önemlidir. Ancak kültürlerde üremenin görülmesi ve tür tayini zor olabilir ve uzun zaman alabilmektedir. Kandidemi için kan kültürlerinin sadece \%50-70'inde üreme görülebilmektedir. $^{13}$

$\mathrm{Bu}$ retrospektif çalışmada, hastanemizin kandidemi ile ilgili lokal epidemiyolojik verilerinin belirlenmesi, kandi- demi gelişimi ve mortalite ile ilişkili risk faktörlerinin saptanması amaçlanmıştır.

\section{GEREÇ ve YÖNTEM}

Yoğun bakım ünitemiz toplam 70 yataklıdır ve 3. basamak olarak hizmet vermektedir. 1 Şubat 2020-01 Şubat 2021 tarihleri arasında yoğun bakımda yatan toplam 1085 hasta dosyası retrospektif olarak tarand1. Klinik belirti ve bulgular ile birlikte en az bir kan kültüründe kandida türünün izole edilmesi kandidemi olarak tanımlandı. Hastaneye yatış tarihi ile pozitif kan kültürü tarihi arasındaki süre $\geq$ 48 saat olan hastalarda gelişen kandidemi hastane kökenli olarak kabul edildi. Kan kültürlerinin biri veya birkaçında kandida izole edilen 30 hastanın demografik verileri ve eşlik eden hastalıkları ilgili formlara kayıt edildi. Bir hastadaki birden fazla üremeler tek bir üreme kabul edildi. Üremeden önceki bir aylık sürede kullandığı geniş spektrumlu antibiyotiklerin grubu ve süresi, steroid kullanımları,total parenteral nütrisyon (TPN) alımı, santral venöz kateter (SVK) kullanımları, abdominal cerrahi geçmişi, yoğun bakımda kalış süreleri açısından hastane veri arşivinden incelendi. Kandidemi gelişimi için risk oluşturan faktörlerin analizi, kandidemi gelişimine kadar olan süreçte elde edilen verilerden yola çıkılarak yapıldı. Çalışmaya 18 yaş üzeri hastalar dahil edildi ve üreme sonrası 30 günlük sağ kalım dönemleri hastane elektronik veri arşivinden izlendi. Kan kültürlerinde maya ürediği tarihden sonraki 30 günde gerçekleşen ölüm "mortalite” değerlendirmesi için tarandi.

Kan kültürlerinde üreyen mayalar VITEK 2 Compact System (BioMérieux, Fransa) otomatize identifikasyon sistemi ile tiplendirildi.

Çalışmada verilerin analizi için Statistical Package for Social Sciences (SPSS) 25.0 paket programı kullanıldı. Sürekli değişkenler median(min-max) şeklinde verildi. Grupların karşılaştırılmasında Mann Whitney U tesit kullanıldı. $\mathrm{p}<0.005$ istatistiksel olarak anlamlı kabul edildi. 
Etik kurul onayı Akdeniz Üniversitesi Tıp Fakültesi Klinik Araştırmalar Etik Kurulundan (05.05.2021 \No286) alındı.

\section{BULGULAR:}

Bir y1l içerisinde yoğun bakım ünitesine toplam 1085 hasta yatışı ve bunların 30'unda $(\% 2,76)$ kan kültüründe Candida spp. ürediği saptandı. İzolatların 9’unu (\%30) C.albicans ve 21 'ini (\%70) Albicans dışı kandidalar oluşturdu. Albicans dışı kandidaların 15’i(\%50) C.parapsilosis, 4'ü $(\% 13,3)$ C.tropicalis ve 2'si $(\% 6,6)$ C.glabrata idi. Hastaların 14’ü $(\% 46,6)$ kadın ve 16'sı $(\% 53,3)$ erkekti, yaş aralığı $74 \pm 18$ idi. Yoğun bakımda yatış süreleri ortalama 147,8 $\pm 134,4$ gündü. Hastaların tümünde üriner kateterizasyon mevcuttu ve non nötropeniktiler. 10 hastanın kan ve idrar kültüründe aynı kandida türü ve 8 hastanın da kan, aspirat ve idrar kültüründe aynı etken saptandı. Hastaların kan kültürlerinde kandida izolasyonundan önceki 30 günlük süreçte sahip oldukları risk faktörleri Tablo-1'de ve üreme öncesi yine 30 günlük dönemde kullandıkları antibiyotikler Tablo-2'de gösterilmiştir. Hastaların hepsinde en az bir ek hastalık mevcut olup; 27 hastada kardiyovasküler hastalık(konjestif kalp yetmezliği, koroner arter hastalığı, hipertansiyon), 14'ünde Kronik nörolojik hastalık(demans, alzheimer, serebrovasküler hastalık), 12'sinde diyabet, 10'unda kronik akciğer hastalığg (kronik obstrüktif akciğer hastalığı,kronik bronşit) ve 3'ünde malignite mevcuttu. Kandidemi gelişen hastaların 27’si (\%90) takip eden 30 günlük zamanda kaybedildi. Hasta yatışından kan kültüründe candida izolasyonuna kadar olan süreler C.albicans ve Albicans dışı kandidalar için karşılaştırılmış ve anlamlı bir fark bulunamamıştır (Tablo 3). Kan kültüründe candida izolasyonundan ölüme kadar olan süreler C.albicans ve Albicans dışı kandidalar için karşılaştırılmış ve anlamlı bir fark saptanmamıştır (Tablo 4).

\section{TARTIŞMA}

Kandidemi gerek invaziv işlemlerin çokluğu gerekse risk faktörlerinin artmış olmasından dolayı sıklıkla yoğun bakım ünitelerinde görülmektedir. Nozokomiyal mantar enfeksiyonlarının sıklığı özellikle son yıllarda artış göster- miştir. Hastanelere göre farklı sonuçlar olmakla birlikte, kandida türlerinin hastane kaynaklı kan dolaşım sistemi enfeksiyonlarının (KDSİ) \%3-15’inden sorumlu olduğu ve etken olarak dördüncü sıklıkta izole edildiği bildirilmektedir. ${ }^{14,15}$ Yapılan çalışmalarda kandidemiye atfedilmiş olan mortalite \%60-80 gibi yüksek oranda rapor edilmiştir. ${ }^{16}$

\begin{tabular}{|l|c|c|}
\hline \multicolumn{3}{|l|}{$\begin{array}{l}\text { Tablo 1: Hastaların candida izolasyonundan önceki } 30 \text { günlük } \\
\text { dönemde sahip oldukları risk faktörleri }\end{array}$} \\
\hline & $\mathrm{n}(\%)$ & Süre (gün) \\
\hline $\begin{array}{l}\text { Geniş spektrumlu } \\
\text { antibiyotik kul- } \\
\text { lanımı }\end{array}$ & $30(100)$ & $22 \pm 7.5$ \\
\hline $\begin{array}{l}\text { YBÜ de 10 günden } \\
\text { fazla yatış }\end{array}$ & $27(90)$ & $66 \pm 48$ \\
\hline Entübasyon süresi & $27(90)$ & $37 \pm 28$ \\
\hline SVK & $15(23,3)$ & $17 \pm 8.4$ \\
\hline TPN & $7(23,3)$ & $9.6 \pm 7$ \\
\hline Steroid kullanımı & $5(16,6)$ & $10 \pm 3.7$ \\
\hline $\begin{array}{l}\text { TPN: Total parenteral nütrisyon } \\
\text { SVK: santral venöz kateter. }\end{array}$ \\
\hline
\end{tabular}

Tablo 2: Candida izolasyonundan önceki 30 günde antibiyotik kullanımı

\begin{tabular}{|l|c|c|}
\hline Antibiyotik grupları & $\mathrm{n}(\%)$ & Süre (gün) \\
\hline Karbapenem & $30(\% 100)$ & $16 \pm 9,2$ \\
\hline Glikopeptid & $30(\% 100)$ & $15 \pm 5,3$ \\
\hline Piperasilin-tazobaktam & $26(86,6)$ & $10 \pm 4$ \\
\hline Linezolid & $20(\% 66,6)$ & $10 \pm 7,3$ \\
\hline Tigesiklin & $7(23,3)$ & $7 \pm 4$ \\
\hline Kinolon & $5(16,6)$ & $7 \pm 3,8$ \\
\hline Aminoglikozid & $5(16,6)$ & $5 \pm 2$ \\
\hline Metronidazol & $2(\% 6,6$ & $4 \pm 2,3$ \\
\hline
\end{tabular}

\begin{tabular}{|c|c|c|c|c|c|}
\hline & \multicolumn{2}{|c|}{ Albicans $(n=9)$} & \multicolumn{2}{|c|}{ Non-albicans $(\mathrm{n}=21)$} & $\mathrm{p}$ \\
\hline & ort \pm ss & $\begin{array}{c}\text { median } \\
(\min - \\
\max )\end{array}$ & ort \pm ss & $\begin{array}{c}\text { median } \\
(\min - \\
\max )\end{array}$ & \multirow[b]{2}{*}{0.221} \\
\hline $\begin{array}{l}\text { Yatıştan } \\
\text { sonra } \\
\text { üreme } \\
\text { (gün) }\end{array}$ & $26.55 \pm 14.18$ & $\begin{array}{c}20,5 \\
(15-50)\end{array}$ & $35.66 \pm 22.47$ & $\begin{array}{c}27 \\
(5-86)\end{array}$ & \\
\hline
\end{tabular}

ortalama \pm standart sapma, Mann Whitney U test

C.albicans ve non-albicans grupları arasında istatistikçe anlamlı bir farklılık göstermemiştir $(\mathrm{p}=0.221)$. 
Tablo 4: Candida izolasyonundan ölüme kadar olan süre

\begin{tabular}{|c|c|c|c|c|c|}
\hline & \multicolumn{2}{|c|}{ Albicans $(\mathrm{n}=8)$} & \multicolumn{2}{|c|}{ Non-albicans $(\mathrm{n}=19)$} & $\mathrm{p}$ \\
\hline & ort \pm ss & $\begin{array}{l}\text { median } \\
(\min - \\
\max )\end{array}$ & ort \pm ss & $\begin{array}{l}\text { median } \\
(\min - \\
\max )\end{array}$ & \multirow{2}{*}{0.275} \\
\hline $\begin{array}{l}\text { Üremeden } \\
\text { sonra ex } \\
\text { (gün) }\end{array}$ & $11.00 \pm 5.60$ & $10(3-20)$ & $17.31 \pm 14.44$ & $13(5-64)$ & \\
\hline \multicolumn{5}{|c|}{ ortalama \pm standart sapma, Mann Whitney U test } & \\
\hline
\end{tabular}

Bir yıllık dönemde ve üçüncü düzey YBÜ'de yapılan çalışmamızda kandidemi insidansı 1.000 hastada 27,6 ve 30 günlük mortalite oranı \%90 olup, literatürle karşılaştırıldığında yüksek saptanmıştır. Kır ve Bahçeci’nin ${ }^{17}$ yaptığ 1 2020 yılına ait bir çalışmada benzer şekilde kandidemi insidansını 1000 hastada 46 veYBÜ mortalitesini \%78.3 gibi yüksek bir oranda saptamışlardır. Tokak ve $\operatorname{ark}^{18} 2019$ yılında yaptıkları çalışmada da benzer şekilde mortalite oranını \%74,2 olarak tespit etmişlerdir.

Çalışmamızın sadece üçüncü düzey YBÜ’de yapılması, hastalarda kandidemi için risk faktörlerinden birkaçının aynı anda olması ve ileri yaşta olması (ortalama (74 \pm 18$)$ gibi nedenlerle mortalitenin yüksek olduğunu düşünmekteyiz. Hastalardan 8'inin COVID-19 nedeni ile takip edildiklerini ve bu durumun mortalite üzerine olumsuz etkisini de göz ardı etmemek gerekir.

Çalışmamızda saptanan yaş ortalaması $74 \pm 18$ yıl olarak belirlenmiştir. Benzer şekilde Tokak ve $\operatorname{ark}^{18}$ kandidemili olguların yaş ortalamasını $73.7 \pm 14.9$ yıl olarak saptamıştir.

Yapılan diğer çalışmalarda yoğun bakım ünitesinde takip edilen kandidemi hastalarının yaş ortalaması çalışmamızla parelelik göstermektedir. ${ }^{19-21}$

Kandideminin en olası mekanizması; gastrointestinal sistem florasında doğal olarak bulunan kandida türlerinin mukozal penetrasyon ile kandidemiye yol açabilmesidir. YBÜ’de mekanik ventilatördeki hastalarda, enteral beslenmede gecikme ve geniş spektrumlu antibiyotik kullanımı, bu olasılığg arttırmaktadır. ${ }^{22,23}$ Çalışmamızda 15 hastada (\%50) SVK kullanımı ve kateter ilişkili kandidemi olduğu düşünüldü. Yedi hastada (\%23) enteral beslenme yerine TPN kullanıldığı ve hastaların tamamında kandidemiden önceki 30 günlük süreçte karbapenem ile birlikte glikopeptid grubu antibiyotik kullanıldığı saptandı.

APACHE II toplam skoru, akut fizyoloji skoru, yaş ve kronik sağlık değerlendirmesi olmak üzere üç alt başlığın toplamından oluşup; en yüksek değer 71'dir. Toplam puan 25 olduğunda \%25 olan mortalite, 35 puan ve üzerinde \%80’e yükselmektedir. ${ }^{24}$ Çalışmamızda APACHE 2 skoru ortalaması 29,6 olarak saptanmış olup öngörülen mortalite oranı oldukça yüksektir.

Çalıșmamızda en sık görülen tür C.parapsilosis (\%50) olarak saptanmış, bunu C.albicans \%30 takip etmiştir. Avrupa'da C.glabrata ve C.parapsilosis en yaygın türler olurken, Akdeniz ülkelerinde C.parapsilosis yüksek oranda görülmektedir. ${ }^{25,26}$ Ülkemizde yapılan çalışmalarda en baskın tür C.albicans olarak belirlenmiş olup bunu C.parapsilosis izlemiştir. ${ }^{19,20}$ Çalışmamızla benzer şekilde Tokak ve $\operatorname{ark}^{18}$ 2019 yılında yaptığı çalışmada en sık kandidemi etkeni olarak ilk sırada \%48,4 C.parapsilosis ve 2. sırada \%32 C.albicans saptamıșlardır. Çiçek Kolak ve ark. 272018 yılında yaptıkları çalışmada benzer şekilde C. albicans'1 \%36,3 olarak bulurken, \%63,7’ini Albicans dışı kandidalar olarak bulmuşlardır. Bu farklılı̆̆ın birçok nedeni olsa da; artmış flukonazol ve venöz kateter kullanımı başlıca nedendir. ${ }^{28}$

\section{SONUÇ}

Kandidemide kan kültürlerinde sadece \%50-70'inde üreme olur. ${ }^{13}$ Üreme olsa da tür düzeyinde tanımlama ve duyarlılık testlerinin sonuçlanması zaman alır. Kandidemi tanısında gecikme ve başlangıç tedavisinin uygun olmaması yüksek mortalite ile ilişkilidir. Çalışmamızda kandidemi görülen hastalarda mortalite oranı $\% 90$ olarak bulundu. 
Hastaların \%50 sinde SVK kullanıldığı, tümünde geniş spektrumlu antibiyotiklerin birlikte ve uzun süreli kullanıldığı görüldü. Ortalama yatış günlerinin $(147,8 \pm 134,4)$ uzun olduğu saptandı. Yoğun bakım ünitelerinde kandidemi gelişimini engellemek için gereksiz ve uzun süreli kateterizasyondan kaçınılmalı, ampirik olarak uzun süreli ve geniş antibiyotik kullanımı önlenmeli ve akılcı antibiyotik uygulamaları kullanılmalıdır, altta yatan başta diyabet olmak üzere metabolik durumlar tedavi edilmelidir.

Çalışmayı maddi olarak destekleyen kişilkuruluş yoktur ve yazarların herhangi bir çıkar dayalı ilişkisi yoktur. 
J Biotechnol and Strategic Health Res. 2021;5(2):148-153

DURMAZ, COŞKUN, Kandidemi Prognoz Ve Risk Faktörleri

\section{Kaynaklar}

1. Tabah A, Koulenti D, Laupland K, et al. Characteristics and determinants of outcome of hospital-acquired bloodstream infections in intensive care units: the EUROBACT International Cohort Study. Intensive Care. Med. 2012; 38(12): 1930-45.

2. Puig-Asensio M, Padilla B, Garnacho-Montero J, et al. Epidemiology and predictive factors for early and late mortality in Candida bloodstream infections: a population-based surveillance in Spain. Clin Microbiol Infect. 2014; 20(4): O245-54.

3. Baykara N, Akalın H, Arslantaş MK, et al. Epidemiology of sepsis in intensive care units in Turkey: a multicenter, point-prevalence study. Crit Care. 2018; 22(1): 93.

4. Colombo AL, Guimaraes T, Sukienik T, et al. Prognostic factors and historical trends in the epidemiology of candidemia in critically ill patients: an analysis of five multicenter studies sequentially conducted over a 9-year period. Intensive Care Med. 2014;40(10): 1489-98.

5. Kett DK, Azoulay E, Echeverria PM, Vincent JL; Extended Prevalence of Infection in ICU Study (EPIC II) Group of Investigators. Candida bloodstream infections in intensive care units: analysis of the extended prevalence of infection in intensive care unit study. Crit Care Med. 2011; 39(4): 665-7.

6. Lortholary O, Renaudat C, Sitbon K, et al. Worrisome trends in incidence and mortality of candidemia in intensive care units (Paris area, 2002-2010). Intensive Care Med. 2014; 40(9): 1303- 12 .

7. Ulu-Kilic A, Alp E, Cevahir F, Ture Z, Yozgat N. Epidemiology and cost implications of candidemia, a 6-year analysis from a developing country. Mycoses. 2017; 60(3): 198-203.

8. Matthaiou DK, Christodoulopoulou T, Dimopoulos G. How to treat fungal infections in ICU patients. BMC Infect Dis. 2015; 15: 205.

9. Ashley ES. Fungal infections in the intensive care unit. In: Pharmacotherapy Self-Assessment Program (PSAP): Critical and Urgent Care. Seventh ed. Book 2. Lenexa, KS: American College ofClinical Pharmacy, 2010: 61-73.

10. Yang SP, Chen YY, Hsu HS, Wang FD, Chen LY, Fung CP. A risk factor analysis of healthcare-associated fungal infections in an intensive care unit: a retrospective cohort study. BMC Infect Dis. 2013; 13: 10.

11. Chakrabarti A, Sood P, Rudramurthy SM, et al. Incidence, characteristics and outcome of ICU-acquired candidemia in India. Intensive Care Med. 2015; 41(2): 285-95.

12. Morrell M, Fraser VJ, Kollef MH. Delaying the empiric treatment of Candida bloodstream infection until positive blood culture results are obtained: a potential risk factor for hospital mortality. Antimicrob Agents Chemother. 2005; 49(9): 3640-5.

13. Calandra T, Roberts JA, Antonelli M, Basetti M, Vincent JL. Diagnosis and management of invasive candidiasis in the ICU: an updated approach to an old enemy. Crit Care. 2016; 20(1): 125-30.

14. Pfaller M, Diekema D. Epidemiology of invasive candidiasis: a persistent public health problem. Clin Microbiol Rev. 2007;20(1):133- 63.
15. Eggimann P, Francioli P, Bille J, Schneider R, Wu MM, Chapuis G, et al. Fluconazole prophylaxis prevents intra-abdominal candidiasis in high-risk surgical patients. Crit Care Med. 1999;27(6):1066-72.

16. Karabinis A, Hill C, Leclercq B, Tancrede C, Baume D, Andremont A. Risk factors for candidemia in cancer patients: a case-control study. J Clin Microbiol 1988;26:429-32

17. Kır S, Bahçeci BK, Medikal yoğun bakım ünitesinde kandidemi ile ilişkili prognostik fak törlerin değerlendirilmesi J Surg Med. 2020;4(10):870-874.

18. Semih Tokak, Doğaç Uğurcan, Mustafa Agah Tekindal Erișkin yoğun bakım ünitesinde yatan hastalarda kandidemi risk faktörlerinin belirlenmesi Flora derg 2020;25(1):47-53.

19. Mermutluoglu C, Deveci O, Dayan S, Aslan E, Bozkurt F, Tekin R. Antifungal susceptibility and risk factors in patients with candidemia. Eurasian J Med 2016;48:199-203.

20. Tukenmez Tigen E, Bilgin H, Perk Gurun H, Dogru A, Ozben B, Cerikcioglu N, et al. Risk factors, characteristics, and outcomes of candidemia in an adult intensive care unit in Turkey. Am J Infect Control 2017;45:e61-e63.

21. Eliakim Raz N, Babaoff R, Yahav D, Yanai S, Shaked H, Bishara J. Epidemiology, microbiology, clinical characteristics, and outcomes of candidemia in internal medicine wards-a retrospective study. Int J Infect Dis 2016;52:49-54.

22. Arendrup MC, Sulim S, Holm A, Nielsen L, Nielsen SD, Knudsen JD, et al. Diagnostic issues, clinical characteristics, and outcomes for patients with fungemia. J Clin Microbiol 2011; 49: 3300-8.

23. Yang SP, Chen YY, Hsu HS, Wang FD, Chen LY, Fung CP, et al. A risk factor analysis of healthcare-associated fungal infections in an intensive care unit: a retrospective cohort study. BMC Infect Dis 2013; 13: 1-10.

24. Knaus WA, Draper EA, Wagner DP, Wagner DP. APACHE II: A severity of disease classification system. Crit Care Med 1985; 13(10):818-829.

25. Tortorano A, Prigitano A, Lazzarini C, Passera M, Deiana ML, Cavinato S, et al. A 1-year prospective survey of candidemia in Italy and changing epidemiology over one decade. Infection 2013;41:655-62.

26. Arendrup MC, Dzajic E, Jensen RH, Johansen HK, Kjaeldgaard P, Knudsen JD, et al. Epidemiological changes with potential implication for antifungal prescription recommendations for fungaemia: data from a nationwide fungaemia surveillance programme. Clin Microbiol Infect 2013;19:e343-53.

27. Çiçek Kolak Ç ve ark.Akdeniz üniversitesi hastanesỉnde izlenen yetişkin hastalarda kandidemi epidemiyolojisi, candida türlerinin antifungal duyarlılıkları ve mortalite üzerine etkisi Klimik Derg. 2019;32(3):250-8.

28. Rodloff A, Koch D, Schaumann R. Epidemiology and antifungal resistance in invasive candidiasis. Eur J Med Res 2011;16:187-95. 